\title{
Erratum to: Students in Twentieth-Century Britain and Ireland
}

\author{
Jodi Burkett
}

\section{Erratum to:}

J. Burkett (ed.), Students in Twentieth-Century Britain and Ireland, https://doi.org/10.1007/978-3-319-58241-2

In the original version of the book, the following corrections have been incorporated:

In Bertie Dockerill's chapter, the personal address in the footer has been replaced with "Department of Geography and Planning, University of Liverpool, Liverpool, UK".

Email addresses of all the authors have been removed in all the chapters.

Editors and Contributors page has been updated with the newly provided information.

The erratum book has been updated with the changes.

The updated online version of this book can be found at https://doi.org/10.1007/978-3-319-58241-2

(C) The Editor(s) (if applicable) and The Author(s) 2018 